\section{Raw Material}

\section{Outlook Good}

$$
\text { For }
$$

\section{Western Steelmaking}

\author{
by S. G. Sargis
}

T HE rapid expansion of the west as a result of the second world war resulted in a large increase of steel-consuming units in the western states. To meet this demand steel plants at Geneva, Utah; Fontana, Calif.; and other places were built. These new steel plants require raw materials and it is essential that mining development keep pace with steel plant expansion. The basic raw materials for steelmaking are primarily iron ore, coking coal, and limestones.

These materials must be available economically in large quantities to continuously support a local steel industry. Other materials such as manganese and fluorspar, used in lesser quantities though of vital importance, if not available locally can be procured at greater distances from the scene of operations. Scrap is another important raw material in steel production. It replaces pig iron and hot metal in the steel furnaces and offsets the use of a much larger tonnage of iron ore. Scrap production increases with growth in population. As the western population increases, more scrap will be available. However, a large steel industry is not built and maintained just on the amount of scrap available, but must depend on the steady availability of the fundamental basic raw materials-iron ore, coking coal, and limestones.

A quick review of the status of development of basic raw materials as they are known in the west today will indicate the region's expectations.

Coking Coals: The coking coal problem is one of source and selection of deposits which best fit into the current economic picture. At present the chief sources of coking coals are Utah and Colorado. In addition, relatively good coking coals exist in quantity in New Mexico and Washington.

Limestones: The situation for limestones, both calcium and dolomitic, is much the same as for coking coals. Again it is a problem of sources best fitted to the current economic picture.

Iron Ore Reserves: More reliable facts covering the occurrences of this fundamental raw material in the west will develop in time. Currently, a listing of almost all known deposits of iron ore occurrences in the western states, when the estimated tonnages are totaled, shows a figure of some 600 million tons.
A substantial portion of this estimated tonnage is based on limited exploratory data. More sound physical exploration data are required for future evaluation. The estimate includes numerous deposits now believed to contain under 5 million tons each, occurring in difficult terrain at considerable distances from present railroads. More work is required to determine if there are factors which may make them ore sources in the future. Nevertheless, the potential is there and the possibility of increasing iron ore reserves through discovery of additional deposits large enough to support the necessary investment in railroads, plants, and other facilities will be a matter of broad interest for many years. An interesting phase is the possibility of hidden deposits. In noting the nature of the deposits included in the 600 million ton estimate it was found that most of them outcrop at the surface. Experience in Michigan, Wisconsin, Minnesota, and other localities in the United States, where iron ore has been mined for many years, shows that many of the larger orebodies originally showed no surface outcrop. Similar discoveries throughout the West could greatly increase reserves because only a small part of the iron-bearing regions have been competently explored for sub-surface deposits.

A cheap, rapid, and effective method of finding sub-surface iron ore deposits is available for such work. This is the magnetometer, a geophysical instrument which measures anomalies in the earth's magnetic field caused by the presence of magnetic bodies. Western ores, for the most part, possess enough magnetite to make them detectable by the use of the magnetometer. In competent hands and with correct analysis of the magnetic data the magnetometer makes it possible to tell within satisfactory limits whether the magnetic mass causing the anomalies is of commercial size and worth drilling to determine its grade and check the predicted tonnage. The magnetic method of exploring for iron ores greatly increased the efficiency of exploration work. The result has been that extensive work over barren areas can be entirely eliminated. Reasonably speaking, existing orebodies need not remain undiscovered in view of the low cost of prospecting. A sense of the value of this method can be obtained by comparing predicted results, before physical exploration work, with actual results after the deposits have been drilled.

Efficient use will increase the life of available raw materials. The amount of coke required to produce a ton of iron is greatly reduced by better preparation of raw materials which go into blast furnaces. It is found that mixing low volatile coals from other districts, and even noncoking coals from the west, with western high volatile coking coals, will produce an improved and acceptable coke. Manganese and iron, from slags formerly discarded, are recovered in many present practices. Blending and mixing high grade ores with poorer grade ores, through bedding systems, increased potential ore supplies. Improved mining and metallurgical methods provide better extractions and recoveries at both mine and mill. Better steel is made to meet special needs. Greater service from the products resulting from conversion of iron ore, coal, and limestones is obtained than ever before.

S. G. SARGIS is Supervisor of Raw Materials for Columbia-Geneva Steel Div., U. S. Steel Co. This paper was presented at the Pacific Northwest Conference, AIME, Spokane, Wash. 